\title{
Characterizing the photosynthetic ability of the submergence-tolerant rice variety of Inpari30 via maximum quantum yield performance during transient flooding
} stress and recovery

\author{
Arinal Haq Izzawati Nurrahma ${ }^{1}$, Shin Yabuta ${ }^{2}$, Ahmad Junaedi ${ }^{3}$, Jun-Ichi Sakagami ${ }^{2 *}$ \\ ${ }^{1}$ The United Graduate School in Agriculture Sciences, Kagoshima University, Kagoshima, Japan \\ ${ }^{2}$ Faculty of Agriculture, Kagoshima University, Kagoshima, Japan \\ ${ }^{3}$ Faculty of Agriculture, Bogor Agricultural University, Bogor, Indonesia
}

*Corresponding author: sakagami@agri.kagoshima-u.ac.jp

\begin{abstract}
Submergence is an environmental challenge for crop cultivation which causes physiological perturbation and yield loss. Tolerant genotypes are characterized by the ability to maintain physiological processes, especially photosynthesis, minimizing the negative effects of flooding stress. This experiment was aimed to examine the photosynthetic ability during submergence and a recovery period in rice variety of Inpari30 (carrying gene Sub1) compared to IR72442 (an elongation type) under control and submergence treatment. A randomized complete block design was employed in this experiment with three replications. The first factor was the environmental condition consisting of control and submergence. The second factor was rice varieties consisting of Inpari30 and IR72442. Fourteen-day-old seedlings were submerged under $35 \mathrm{~cm}$ of water depth for 6 days and re-aerated by lowering the water level up to the stem base for 6 days of recovery. Measurement of plant height, SPAD, Fv/Fm and photosynthetic rate were taken continuously from the same plant sample following the experimental stage. The results showed that shoot length increased significantly more in IR72442 than in the quiescent Inpari30. The noticeable decline was observed in the photosynthetic rate of both varieties during submergence with chlorophyll content and chlorophyll fluorescence (Fv/Fm) decreased more severely in IR72442 than in Inpari30. After flooding, Inpari30 adapted quickly to the aerobic environment, as shown by a recovery in Fv/Fm and accumulated dry weight more quickly than IR72442. We concluded that the Sub1 genotype of Inpari30 confers the ability to maintain maximum quantum yield of PSII under conditions of limiting gas exchange for photosynthesis for adapting post submergence.
\end{abstract}

Keywords: Sub1A, elongation, Fv/Fm, rice submergence, flash flooding.

Abbreviations: DAS_days after seeding.

\section{Introduction}

Complete submergence is defined as a condition when the entire plant is fully and continuously submerged underwater for 7-14 days (Das et al., 2005; Nishiuchi et al., 2012). Submergence limits plant growth through slow diffusion because the rate of oxygen diffusion is reduced underwater (Amstrong, 1979; Jackson et al., 1984), which inhibits metabolic processes (Setter et al., 1989). A transient flooding event perturbs plant metabolism twice: once during submergence and again during the re-aeration that occurs after the water recedes triggering internal stresses that affect plant growth and survival (Pradhan and Mohanty, 2013). When a plant becomes submerged, the environment becomes limited to gas diffusion and low light intensity, which together result in oxygen deficiency, decreased transpiration, and starvation. Upon re-aeration, the plant is exposed to a sudden excess of oxygen and relatively high light intensity, which leads to oxidative stress and dehydration (Panda and Sarkar, 2012; Tamang and Fukao, 2015).
Any sudden decrease in gas diffusion is a major problem for plants, limiting the photosynthesis and respiration processes that require oxygen and carbon dioxide as substrates (Pradhan and Mohanty, 2013). Among photosynthesis variants, photosystem II (PSII) is known to be the most sensitive to environmental changes, including submergence before irreversible damage becomes apparent (Sayed, 2003). Damage to PSII can be detected by observing the potential maximum quantum yield (proportional to the Fv/Fm ratio, a measure of chlorophyll fluorescence), which generally decreases in plants suffering environmental stress. In general, a decline in $\mathrm{Fv} / \mathrm{Fm}$ is an expression of a photoinhibition phenomenon (Björkman and Demmig, 1987) involving not only photodamage to the photosynthetic system, but also acting as a photoprotective mechanism (Krause and Weis, 1991). The chlorophyll fluorescence parameter Fv/Fm has been widely used for measurement of maximum quantum yield of PS II, as it is a non-invasive technique suitable for studying the tolerance of the photosynthetic apparatus to environmental constraints (Van 
Kooten and Snel, 1990; Murchie and Lawson, 2013). Fluorescence emission is indicative of the composition of the antenna system used in photosynthesis, which is influenced by chlorophyll content per leaf area (Lichtenthaler et al., 1986). Chlorophyll fluorescence induction provides information on almost all aspects of photosynthesis in PSII and the response of plants to environmental factors such as stress and nutrient availability (Björkman and Demmig, 1987; Krause and Weis, 1991; Zhu et al., 2005). Three functions of chlorophyll are important for plant growth during photosynthesis: light absorbance, transfer of the light energy by resonance energy transfer into a specific chlorophyll pair in the reaction centre of the photosystem, and facilitation of the charge separation leading to biosynthesis (Eugene and Govindjee, 1965; Murchie and Lawson, 2013).

Rice variety of Ciherang is widely grown by the farmer in lowland rice field in Indonesia which sensitive to unexpected inundation (Nugraha et al., 2017; Nurrahma et al., 2017). As the country where rice stands as the main staple food, providing suitable rice variety that able to maintain high yield after exposed by flooding due to uncertainties rainfall is mandatory. It will also promote an approach to increase productivity and intensify of rice production in the less favourable environment, i.e. tidal lowland or coastal which also prone toward submergence (Rumanti et al., 2018).

A major quantitative trait locus (QTL) responsible for submergence tolerance, Sub1, has been widely studied in FR13A rice (Oryza sativa L.) and regarded as conferring submergence tolerance in rice breeding ( $\mathrm{Xu}$ and Mackill, 1996; Xu et al., 2006; Panda and Sarkar, 2012). For example, the development of submergence tolerance through introgression of Sub1 into the high yielding rice variety Inpari30 in Indonesia recently resulted in no significant difference from the parental variety (Ciherang) in all traits observed under normal conditions (Septiningsih et al., 2015; Nugraha et al., 2017). However, limited study reported photosynthetic activity following submergence which responsible during recovery and gain assimilates for yield production to characterize newly developed submergence tolerant variety of Inpari30.

The effect of submergence to shoot elongation was tested to 15 genotypes of Oryza sativa for 7 days under $80 \mathrm{~cm}$ water depth resulted the highest ratio of submerged to control plant in IR72442 among all cultivar. Then, this variety used as a typical shoot-elongating cultivar to evaluate the difference of chlorophyll content and chlorophyll fluorescence under submergence compared to non-shootelongating cultivar (Sone et al., 2011). The result concluded that shoot-elongating cultivar was able to maintain the photosynthetic capacity of the newly developed leaf during submergence by prompt reduction of chlorophyll and chlorophyll fluorescence in the leaf that developed before submergence.

In this experiment, we would like to evaluate photosynthetic performance of Inpari30 during submergence following by subsequent reaeration, as a basic understanding to explain the physiological mechanism of Inpari30 overcome submergence stress. Besides, we also aimed to clarify the difference photosynthetic performance between non-shootelongation type of Inpari30 and shoot elongation type of IR72442 by integrating measurements from gas exchange analysis, chlorophyll content (SPAD value), and chlorophyll fluorescence (Fv/Fm).
Results

Effect of submergence on the increase of plant length

Plant length of submerged IR72442 increased significantly more than its control ( $>34.3 \%$ after 6 days of submergence and $>40.9 \%$ by the end of the 6 -day recovery period) and significantly more than both the submerged and control of Inpari30. Conversely, the smaller increase in plant length of submerged Inpari30 was not statistically significant compared to its control. The ratio of plant lengths (after submergence versus control) was 1.23 for IR72442 and 1.02 for Inpari30 (Fig. 1). The slow growth characteristic under submergence conferred by Sub1A was noticeable in the limited change in plant length of Inpari30.

\section{Submergence decreased chlorophyll content (SPAD value)}

The SPAD values for IR72442 decreased significantly versus control $(72.4 \%)$ after submergence whereas those for Inpari30 decreased by only $14.4 \%$ (not significant). The value of all treatment does not change much on recovery. Inpari30 can maintain higher chlorophyll levels after submergence and on recovery. The chlorophyll content of IR72442 decreased during submergence and did not recover well, even after 6 days of re-aeration (Figure 2).

\section{Influence of anaerobic environment on $\mathrm{Fv} / \mathrm{Fm}$ and photosynthesis rate}

Fv/Fm for the control plants of both varieties did not differ significantly during the experiment. After 6 days of submergence, Fv/Fm for IR72442 decreased significantly $(88.9 \%)$, and although the value largely recovered by the end of the 6-day re-aeration period (to 6.11 times the submerged value), Fv/Fm remained significantly lower than the control. After 6 days submergence, Fv/Fm for Inpari30 decreased marginally (not significant) and then increased very slightly after 6 days of recovery (Fig. $3 \mathrm{~A}$ ).

After 6 days of submergence, net photosynthesis for both varieties decreased significantly versus controls $(>41 \%)$, and although photosynthesis recovered to some extent after 6 days of re-aeration (>27.4\%), values remained significantly lower than controls (Fig. 3A).

\section{Total dry weight changes affected by submergence}

Comparison of growth was made via changes in total dry weight during the submergence period and during the recovery period, expressed as the ratio between submerged (S) and control (C) plants. The S/C ratio for Inpari30 was higher than that for IR72442 after submergence and after recovery (Table 1 ).

\section{The ratio of shoot dry weight per shoot length}

The ratio of shoot dry weight and shoot length was the same between varieties and treatment before exposing to submergence. After submergence, submerged IR72442 decreased the ratio significantly lower than control and submerged Inpari30, though no significant difference with control IR72442. After recovery, submerged IR72442 was significantly lower than submerged Inpari30, though there is no significant observed with control plant (Fig. 4). 
The ratio between shoot dry weight and shoot length during the experiment is explained in Fig 4. IR72442 significantly increase plant length after submergence highest among all treatments (Fig. 1). However, the increasing of plant length was not followed by the accumulation of shoot dry weight. Thus, the ratio of shoot dry weight per shoot elongation was lower in submerged IR72442 compared with Inpari30 as shown in Fig. 4.

\section{The changes in photosynthesis rate over SPAD value and Fv/Fm}

The scatterplot figure represents the relationship between variables of submerged Inpari30 and IR72442. Given the significant changes in the photosynthetic rate observed in both varieties, the transition in SPAD value and $\mathrm{Fv} / \mathrm{Fm}$ at Inpari30 is smaller than IR72442 (Fig 5A, 5B). Plant physiological response of SPAD value and $\mathrm{Fv} / \mathrm{Fm}$ to photosynthetic rate $(\mathrm{Pn})$ was lower in Inpari30 than in IR72442. Besides, this shows that the response of SPAD value and $\mathrm{Fv} / \mathrm{Fm}$ is more independent than the photosynthesis rate in explaining the effect of submergence on Inpari30, but not on IR72442.

\section{Discussion}

The effect of submergence commonly does not appear immediately as visual damage, but it soon becomes observable after the water level recedes (Drew, 1997). The first noticeable effect of submergence was the increased plant length of IR72442, greater than Inpari30 in the submergence compared to control (Fig. 1). According to the mechanism of submergence defined by Nagai et al. (2010) and Hattori et al. (2011), the elongation exhibited by IR72442 represents a transient submergence intolerance whereas the relative quiescence exhibited by Inpari30 represents tolerance. Inpari30 carries the gene Sub1A (Septiningsih et al., 2015), which limits plant elongation during submergence, enabling a greater accumulation of shoot dry matter than IR72442 on recovery, as indicated by the $S / C$ ratio (Table 1 ), and it allows the plant to conserve energy for regrowth once the water level subsides. This result contrasts with that of Sarkar et al. (1996) who reported that submergence-tolerant cultivars accumulated more carbohydrates before submergence to elongate the seedling height allowing the production of new carbohydrates as the leaves became exposed to sunlight above the water. In varieties exhibiting shoot elongation, the dry weight of leaves developed before submergence is used for leaf elongation (Kawano et al., 2008). In this study, IR72442 showed extensive shoot elongation, with low ratio of dry weight per shoot elongation (Fig 4), despite a decline in photosynthetic rate observed during submergence (Fig. 2B).

Chlorophyll fluorescence (Fv/Fm) is an effective indicator of submergence tolerance of rice (Sone et al., 2012). In this study, Fv/Fm for the controls (i.e. non-stress conditions) did not differ significantly between Inpari30 and IR72442 (Fig. 2A); therefore, the decrease in Fv/Fm of IR72442 during submergence can be attributed to the submergence treatment. Conversely, net photosynthesis was rapidly decreasing during submergence for both Inpari30 and IR72442 versus controls (Fig. 2B). Significantly decline of Fv value in the susceptible cultivar than tolerant cultivar also reported by Panda et al. (2007) which then assumed that deterioration of PSII in tolerant cultivars was comparatively less than susceptible ones. The decline in Fv/Fm for IR72442 during submergence likely reflects a reduced ability of PSII to reduce the primary acceptor (Panda and Sarkar, 2012). This provides evidence for disorganization of the photosynthetic apparatus and is attributed to a decrease in light intensity and oxygen level in floodwater (Panda et al., 2008; Panda and Sarkar, 2012). This reduction is also indicative of photoinhibition damage in response to environmental stress resulting in a decline in the efficiency of solar energy conversion during photosynthesis in combination with an overall decline in photosynthetic capacity (Maxwell \& Johnson, 2000; Inamullah and Isoda, 2005). Submerged plants of Inpari30 described to maintain absorbing energy from light, however plants declined photosynthetic rate by limiting gas exchange and stomatal closure during anaerobic. After six days of re-aeration, Fv/Fm for the submerged IR72442 recovered but only to a level below that of the controls. However, the tolerant rice variety, Inpari30, was able to adjust to the aerobic environment quickly, as observed from Fv/Fm values (Fig. 2A). During re-aeration, the photosynthetic rate largely recovered from submergence levels in both varieties, but remained significantly below those of controls (Fig. 2B). Variable fluorescence (Fv) equals the fluorescence increase from minimal fluorescence (Fo) to maximal fluorescence (Fm), Fv $=\mathrm{Fm}-\mathrm{Fo}$. Then the maximal quantum yield of PS II Fv/Fm is the function of quantum yield $=(\mathrm{Fm}-\mathrm{Fo}) / \mathrm{Fm}$ (Hall et al., 1993; Panda et al., 2008). Any changes in Fm or Fo would consequence with the change of Fv/Fm. However, the increasing in Fv/Fm of the susceptible variety was not representative of an increase of PSII efficiency, as a substitute of minimal fluorescence (Fo) decreasing compared to maximal fluorescence (Fm) on the measurement observed (Panda et al., 2008). This describes the possible cause of increasing $\mathrm{Fv} / \mathrm{Fm}$ of submerged IR72442 after six days of recovery.

The photosynthetic rate in both varieties decreased during submergence; however, Inpari30 was able to grow effectively after submergence as reflected that the dry weight ratio of submerged to control (Table 1). Shoot dry weight in both varieties declined during flooding treatment, but after just 6 days of re-aeration, shoot dry weight for Inpari30 recovered to the same level as the controls. The higher ratio of shoot dry weight per length on Inpari30 represents that by slow elongation during submergence, this variety able to maintain dry matter (Fig 4). This reflects the results of Sarkar and Bhattacharjee (2011), who found that Sub1 varieties exhibit the ability to maintain higher biomass and can re-grow faster during re-aeration.

The narrow alteration of SPAD value and Fv/Fm explained that the vast changes photosynthesis does not affect both variables at Inpari30, but not at IR72442 (Fig 5A, 5B). This also means that the response of the SPAD value and Fv/Fm is more independent than the photosynthesis rate in explaining the effect of submergence on Inpari30. The vast change of SPAD and Fv/Fm value in IR72442 as the change of photosynthesis rate perhaps related to varietal factors in response to environmental changes during submergence, such as changes of light intensity that reflected by SPAD and Fv/Fm measurements. Light intensity changed from 350 to $330 \mu \mathrm{mol} \mathrm{m} \mathrm{m}^{-2} \mathrm{~s}^{-1}$ during submergence which responded by Inpari30 and IR72442 differently.

Photosynthesis, the transformation of carbon dioxide into organic matter in the presence of plant chlorophylls under 
Table 1. Ratio of total dry weight after submergence and after recovery (re-aeration).

\begin{tabular}{|c|c|c|c|c|}
\hline Treatment & $\begin{array}{l}\text { Total dry weight after } \\
\text { submergence (g plant }{ }^{-1} \text { ) }\end{array}$ & $\mathrm{S} / \mathrm{C}$ ratio & $\begin{array}{l}\text { Total dry weight after } \\
\text { recovery } \\
\text { (g plant }^{-1} \text { ) }\end{array}$ & $\mathrm{S} / \mathrm{C}$ ratio \\
\hline C Inpari30 & 0.0188 & \multirow{2}{*}{$0.76 a$} & $0.0152 \mathrm{~d}$ & \multirow{2}{*}{$2.15 \mathrm{a}$} \\
\hline S Inpari30 & 0.0144 & & 0.0326 a & \\
\hline C IR72442 & 0.0180 & \multirow{2}{*}{$0.59 \mathrm{~b}$} & 0.0242 bc & \multirow{2}{*}{$1.07 \mathrm{~b}$} \\
\hline S IR72442 & 0.0105 & & $0.0259 \mathrm{~b}$ & \\
\hline
\end{tabular}

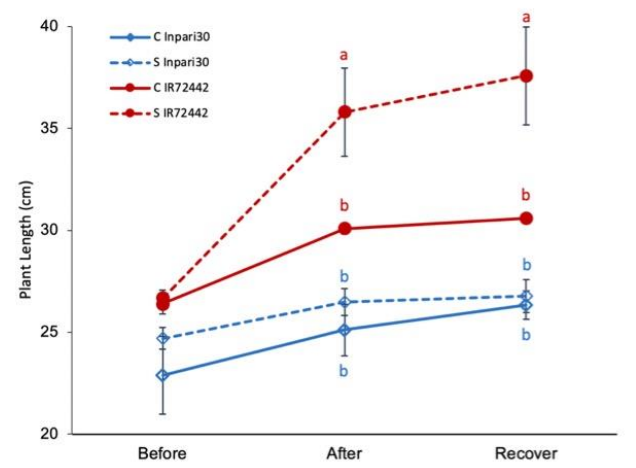

Fig 1. Plant length of two contrasting rice varieties (IR72442, an elongation type; Inpari30, carrying gene Sub1A) before submergence, after submergence, and after recovery (re-aeration). Different lowercase letters in the same column indicate a significant difference at $p<0.05$ with Tukey test. Error bar represent standard deviation from three replications. C, Control; S, Submerged.

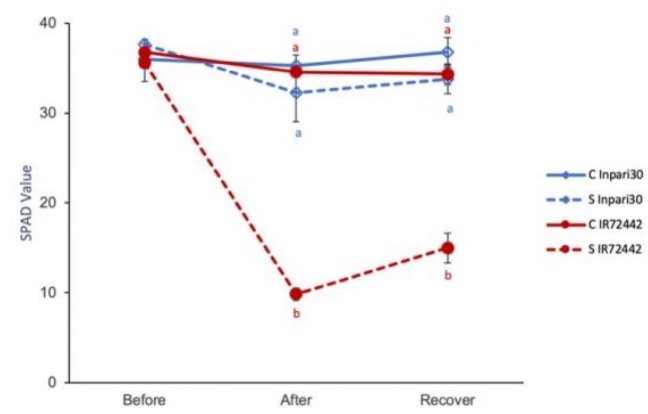

Fig 2. Chlorophyll content (SPAD Value) of two contrasting rice varieties (IR72442, an elongation type; Inpari30, carrying gene Sub1A) before submergence, after submergence, and after recovery (re-aeration). Different lowercase letters in the same column indicate a significant difference at $p<0.05$ with Tukey test. Error bar represent standard deviation from three replications. C, Control; S, Submerged.

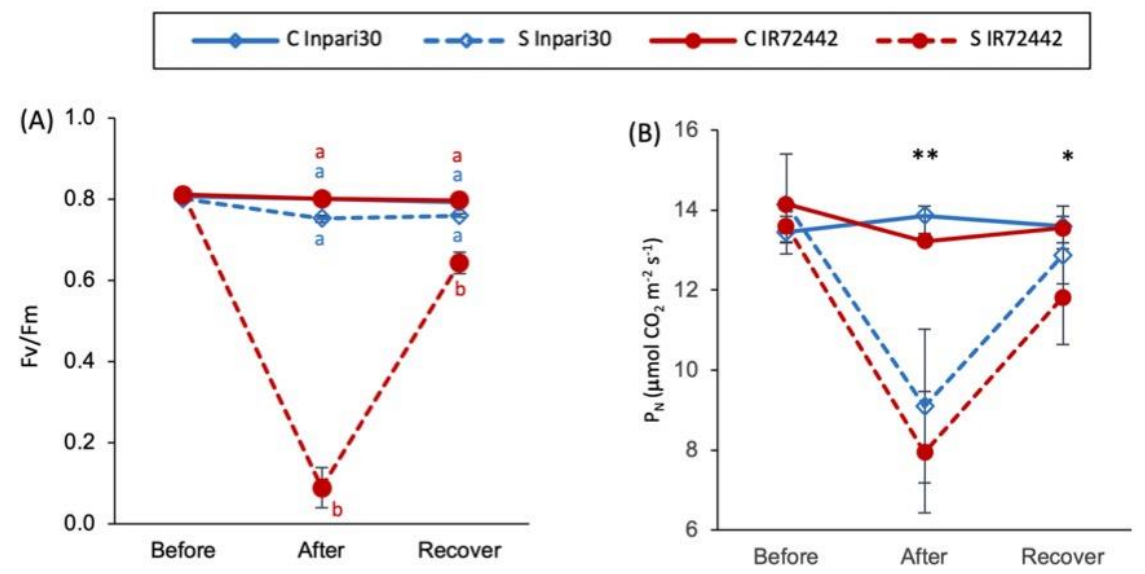

Fig 3. Fv/Fm (A) and net photosynthesis rate (B) of two contrasting rice varieties (IR72442, an elongation type; Inpari30, carrying gene $S u b 1 A$ ) before submergence, after submergence, and after recovery (re-aeration). ${ }^{*}$ and ${ }^{* *}$ in each the stage of observation indicates significance of differences between control and submergence in $p<0.05$ and $p<0.01$, respectively. Different lowercase letters in the same column indicate a significant difference at $p<0.05$ with Tukey test. Error bar represent standard deviation from three replications. C, Control; S, Submerged. 


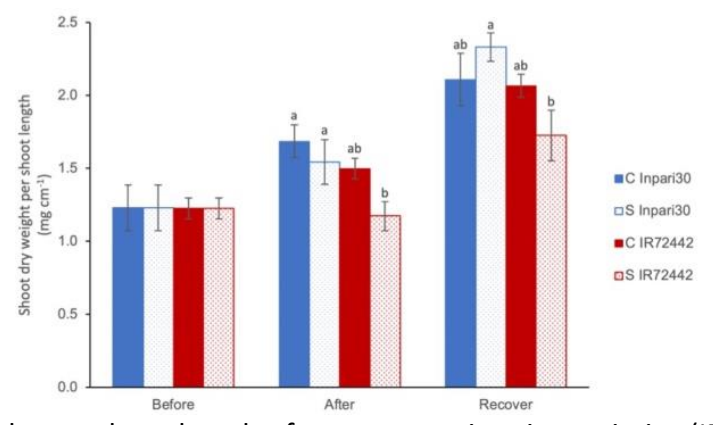

Fig 4. Accumulation of shoot dry weight per shoot length of two contrasting rice varieties (IR72442, an elongation type; Inpari30, carrying gene Sub1A) before submergence, after submergence, and after recovery (re-aeration). Different lowercase letters indicate a significant difference at $p<0.05$ with Tukey test. Error bar represent standard deviation from three replications. C, Control; S, Submerged.
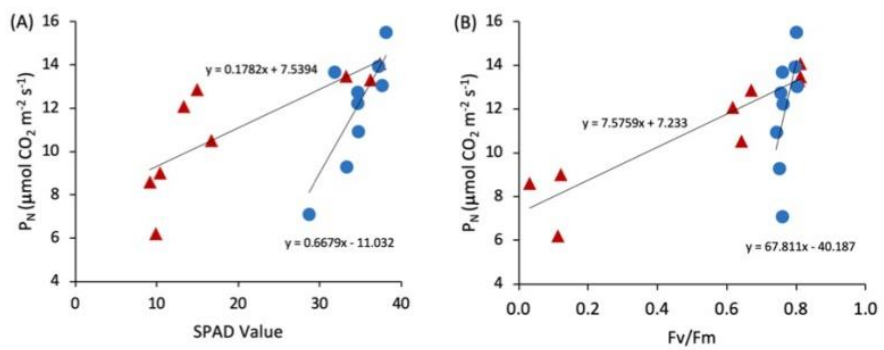

Fig 5. Relationship between net photosynthesis and (A) SPAD value, and (B) Fv/Fm of submerged Inpari30 and IR72442 rice plants. Triangle shape represent submerged IR72442 and circle represent submerged Inpari30.

the influence of light, involves the release of oxygen from water (Gest, 2002). Chlorophyll converts the energy from captured light photons into chemical energy that is used to drive $\mathrm{CO}_{2}$ fixation (Murchie and Lawson, 2013). Under laboratory conditions, the transport of PSII electron and the fixation of $\mathrm{CO}_{2}$ can be very well associated. However, this connection may result in difference under field condition. Differences can be caused by changes in the relative levels of $\mathrm{CO}_{2}$ fixation and by competing processes such as photorespiration, nitrogen metabolism and oxygen donation (Maxwell and Johnson, 2000). The electrons released during the photochemical process are not always used for carbon fixation when environmental factors perturb $\mathrm{CO}_{2}$ availability (e.g. under anaerobic conditions, stomatal closure, etc.). In these circumstances, the excitation of electrons could be considered as a waste of energy, potentially producing reactive oxygen species leading to oxidative stress. The disturbance of electron transfer can be recognized from decreasing quantum yield of electron transfer in PSII (Fv/Fm), this was observed during submergence in IR72442 but not in Inpari30 despite the photosynthetic rate being in decline in both (Fig. 2A; 2B) and the relation both variables explained (Fig 5B). This means that even though Fv/Fm could identify PSII efficiency in a tolerant variety, it could not be used to predict an accurate determination of $\mathrm{CO}_{2}$ fixation with fluorescence alone is not possible (Maxwell and Johnson, 2000).

\section{Material and methods}

\section{Location}

The research was conducted from June to July 2018, in controlled room conditions at the Tropical Crop Science Laboratory, Kagoshima University, Japan. The daily temperature during the experiment was maintained $27^{\circ} \mathrm{C}$ with $350 \mu \mathrm{mol} \mathrm{m}{ }^{-2} \mathrm{~s}^{-1}$ of $12 \mathrm{~h}$ light exposure.

\section{Experimental design}

A randomized complete block design was employed in this experiment. Two factors were studied. The first factor was environmental conditions: control versus submergence. The second factor was rice variety, which was fully randomized on the environmental conditions. To compare different tolerance mechanisms during complete submergence followed by several days of re-aeration, we used rice variety Inpari30 as a Sub1A genotype and variety IR72442 as an elongation type. The experiment was conducted in three replications.

\section{Experimental setup and conduction}

Rice seeds of Inpari30 and IR72442 were soaked and incubated for three days at $30^{\circ} \mathrm{C}$. Germinated seeds were then sown into commercial soil for rice seedling ( $N: P: K=$ 0.9:2.3:1.1; $\mathrm{pH} 4.5-5.2$ ) in a growth chamber. Ten-day-old seedlings were transplanted into a sponge and inserted into a seedling tray inside experimental glass containers. The water level was maintained at $4.5 \mathrm{~cm}$ from the container base, the same level as the seedling tray surface also the plant stem base. The experiment was conducted in a controlled room with $12 \mathrm{~h}$ light exposure at $350 \mu \mathrm{mol} \mathrm{m} \mathrm{m}^{-2} \mathrm{~s}^{-1}$ measured $20 \mathrm{~cm}$ above the tray surface and at $27^{\circ} \mathrm{C}$ (Day/Night). However, under submergence the light exposure was approximately $200 \mu \mathrm{mol} \mathrm{m} \mathrm{m}^{-2} \mathrm{~s}^{-1}$ lower. The oxygen concentration at the same water depth was ranging from 7.0-8.9 $\mathrm{mg} \mathrm{L}^{-1}$ during the experiment.

At 14 days after seeding (DAS), when the third leaf was fully expanded, the water level in the glass container was raised 
to $35 \mathrm{~cm}$ above the shoot base for the plants receiving treatment, while the water level for the control plants was maintained as height as the stem base. Treatment was stopped after 6 days (20 DAS), at which point the water level for treatment and control was maintained at the same level, adjusted to the stem base. The recovery stage lasted 6 days which after that all the plants were removed from their containers (i.e. at 26 DAS). Seedlings were only exposed by submergence only for 6 days allowing measurement the whole process of stress effect and recovery without plant death as the worst effect of continuous submergence. Measurement of Fv/Fm, SPAD value and photosynthesis rate were performed on the same leaf, the 3rd leaf, as the fully expanded leaf before treatment started, those the developing of 3rd leaf during submergence and recovery could be used to evaluate the effect of stress exposure. Tillers were not developed yet during the whole experiment therefore data were not available.

\section{Variables analysed}

\section{PS II quantum yield (Fv/Fm)}

After 2 hours of dark adaptation, equipment to measure chlorophyll fluorescence (AquaPen-P AP-P 100, PSI, Czech Republic) was attached to the third leaf of the rice plant being sampled. The maximal quantum yield of PS II photochemistry (Fv/Fm) was obtained by actinic light emission through the quantum yield (QY) menu. Variable fluorescence (Fv) equals the fluorescence increases from minimal fluorescence (Fo) to maximal fluorescence (Fm), Fv $=\mathrm{Fm}-\mathrm{Fo}$. Then the maximal QY of PS II Fv/Fm is the function of $Q Y=(F m-F o) / F m$ (Hall et al., 1993; Panda et al., 2008). Any changes in Fm or Fo would consequence with the change of Fv/Fm. The maximal fluorescence (Fv/Fm) value is 0.85 that equals $85 \%$ efficiency of the conversion of absorbed light into photochemistry.

\section{Leaf chlorophyll content (SPAD value)}

The amount of chlorophyll present in leaves was estimated using a leaf chlorophyll meter (SPAD-502, Konica Minolta Corporation, Japan). The chlorophyll content was represented by the average Soil Plant Analysis Development (SPAD) value of three measurements on the tip, middle, and base of the third leaf. The strong relationship between SPAD index and leaf chlorophyll concentration has been widely reported on several. This tool measures the chlorophyll content of the leave without destruction, simple, quick, and portable. Moreover, a significant linear regression line was reported between SPAD reading and chlorophyll content in rice (Kumagai et al., 2009). The leaf chlorophyll content is affected by $\mathrm{N}$ status in the plant that commonly has a strong positive relationship with the photosynthetic rate (Sinclair and Horie, 1989). Therefore, SPAD reading is possible to use as an indirect countermeasure of photosynthetic capacity on the rice leaf.

\section{Plant length $(\mathrm{cm})$}

The length of each plant sampled was measured from the stem base to the highest shoot tip using a ruler. The data presented are the average from 12 plant samples in three replicates.

\section{Gas exchange measurements}

Measurement of net photosynthesis $\left(\mathrm{P}_{\mathrm{N}}\right)$ was assessed using a portable photosynthesis analysis system (LI-6400; LI-COR, Lincoln, NE, USA). Before measurements were made, plant samples were adapted under light exposure of 300-350 $\mu \mathrm{mol} \mathrm{m} \mathrm{m}^{-2} \mathrm{~s}^{-1}$ same as growth environment condition. The third leaf of each sample was selected and kept inside the chamber until a stable reading was recorded. Leaf area was measured to calculate the gas exchanges rate per observed area. During measurement, relative humidity was $\sim 50 \%$, leaf temperature $25^{\circ} \mathrm{C}$, ambient $\mathrm{CO}_{2}$ concentration $\sim 400 \mu \mathrm{mol}$ $\mathrm{mol}^{-1}$, airflow through the chamber was maintained at 500 $\mu \mathrm{mol} \mathrm{s} \mathrm{s}^{-1}$, and photosynthetic photon flux density (PPFD) $1100 \mu \mathrm{mol} \mathrm{m} \mathrm{m}^{-2} \mathrm{~s}^{-1}$.

\section{Total dry weight (g)}

Four plant samples from each replicate were acquired for total dry weight measurement. The plant samples were put in envelopes and dried in an oven for $72 \mathrm{~h}$ at $80^{\circ} \mathrm{C}$. The ratio $\mathrm{S} / \mathrm{C}$ (submerged/control) for weight change was then calculated for the period of submergence and the period of recovery.

\section{Statistical analysis}

Data were analysed from three replications using two ways of analysis of variance. If significant differences were found, the Tukey test was performed at $p=0.05$.

\section{Conclusion}

Submergence decreased net photosynthesis both Inpari30 and IR72442. However, Inpari30 maintain stable shoot elongation as well as $\mathrm{Fv} / \mathrm{Fm}$ and SPAD value during submergence. Plant physiological changes of SPAD value and $\mathrm{Fv} / \mathrm{Fm}$ to photosynthetic rate $(\mathrm{Pn})$ was lower in Inpari30 than in IR72442. Moreover, Inpari30 accumulated higher dry weight per shoot elongation. In conclusion, the Sub1 genotype of Inpari30 confers the ability to maintain Fv/Fm under complete submergence and in conditions limiting gas exchange for photosynthesis.

\section{References}

Amstrong W (1979) Aeration in higher plants. Adv Bot Res. 7:225-332

Björkman O, Demmig B (1987) Photon yield of $\mathrm{O}_{2}$ evolution and chlorophyll fluorescence characteristics at $77 \mathrm{~K}$ among vascular plants of diverse origins. Planta. 170:489-504.

Das KK, Sarkar RK, Ismail AM (2005) Elongation ability and non-structural carbohydrate in relation to submergence tolerance in rice. Plant Sci. 168:131-136

Drew MC (1997) Oxygen deficiency and root metabolism: injury and acclimation under hypoxia and anoxia. Ann Rev Plant Physiol Plant Mol Biol. 48:223-250.

Eugene IR, Govindjee (1965) The role of chlorophyll in photosynthesis. Sci Am. 213:74-83.

Gest H (2002) History of the word photosynthesis and evolution of its definition. Photosynth Res. 73:7-10.

Hall DO, Long SP (1993) In: Hall DO, Scurlock JMO, BolharNordenkampf HR, Leegood RC, Long SP (eds) Photosynthesis and production in changing environment: $\mathrm{a}$ 
field and laboratory manual, $1^{\text {st }}$ edn. Chapman and Hall, London

Hattori Y, Nagai K, Ashikari M (2011) Rice growth adapting to deepwater. Curr Opin Plant Biol. 14:100-105.

Inamullah, Isoda A (2005) Adaptive responses of soybean and cotton to water stress II. changes in $\mathrm{CO}_{2}$ assimilation rate, chlorophyll fluorescence and photochemical reflectance index in relation to leaf temperature. Plant Prod Sci. 8:131-138.

Jackson MB, Drew MC (1984) Effects of flooding on growth and metabolism of herbaceous plants. In: Kozlowski TT (ed). Flooding and plant growth. Academic Press, New York

Kawano N, Ito O, Sakagami JI (2008) Relationship between shoot elongation and dry matter weight during submergence in Oryza sativa L. and O. glaberrima Steud. Rice Cultivar. Plant Prod Sci. 11:316-323.

Krause GH, Weis E (1991) Chlorophyll fluorescence and photosynthesis: the basics. Ann Rev Plant Physiol Plant Mol Biol. 42:313-349.

Lichtenthaler H, Buschmann C, Rinderle U, Schmuck G (1986) Application of chlorophyll fluorescence in ecophysiology. Radiat Environ Bioph. 25:297-308.

Maxwell K, Johnson GN (2000) Chlorophyll fluorescence - a practical guide. J Exp Bot. 51:659-668.

Murchie EH, Lawson T (2013) Chlorophyll fluorescence analysis: a guide to good practice and understanding some new applications. J Exp Bot. 64:3983-3998.

Nagai K, Hattori Y, Ashikari M (2010) Stunt or elongate? two opposite strategies by which rice adapts to floods. J Plant Res. 123:303-309.

Nishiuchi S, Yamauchi T, Takahashi H, Kotula L, Nakazono M (2012) Mechanisms for coping with submergence and waterlogging in rice. Rice. 5:2.

Nugraha $Y$, Hidayatun $N$, Trisnaningsih, Yuliani D, Ardiyanti S, Kadir TS (2017) Phenotypic performance of Ciherang Sub1 near isogenic line as an adaptive variety for flooding condition. Indones J Agri Sci. 18:7-16.

Nurrahma AHI, Junaedi A, Purnamawati H, Sakagami J (2017) Rice root distribution of four rice varieties to different depth of submergence. Agrivita J Agri Sci. 39:119127.

Panda D, Sarkar RK (2012) Leaf photosynthetic activity and antioxidant defence associated with sub1 QTL in rice subjected to submergence and subsequent re-aeration. Rice Sci. 19:108-116.

Panda D, Sharma SG, Sarkar RK (2007) Chlorophyll fluorescence transient analysis and its association with submergence tolerance in rice (Oryza sativa). Indian J Agri Sci. 77:344-8.

Panda D, Sharma SG, Sarkar RK (2008) Chlorophyll fluorescence parameters, $\mathrm{CO}_{2}$ photosynthetic rate and regeneration capacity as a result of complete submergence and sub-sequent re-emergence in rice (Oryza sativa). Aquat Bot. 88:127-133.
Pradhan C, Mohanty M (2013) Submergence stress: responses and adaptations in crop plants. In: Rout GR, Das $A B$ (eds) Molecular stress physiology of plants. Springer, London

Rumanti IA, Hairmansis A, Nugraha $Y$, Nafisah, Susanto $U$, Wardana $\mathrm{P}$, Subandiono RE, Zaini Z, Sembiring $\mathrm{H}$, Khan NI, Singh RK, Johnson DE, Stuart AM, Yoichiro K (2018) Development of tolerant rice varieties for stress-prone ecosystems in the coastal deltas of Indonesia. Field Crop Res. 223:75-82.

Sarkar RK, Bhattacharjee B (2011) Rice genotypes with SUB1 QTL differ in submergence tolerance, elongation ability during submergence and re-generation growth at reemergence. Rice. 5:7.

Sarkar RK, De RN, Reddy JN, Ramakrishnayya (1996) Studies on the submergence tolerance mechanism in relation to carbohydrate, chlorophyll and specific leaf weight in rice (Oryza sativa L.). J Plant Physiol. 149:623-625.

Sayed OH (2003) Chlorophyll fluorescence as a tool in cereal crop research. Photosynthetica. 41:321-330.

Septiningsih EM, Hidayatun $N$, Sanchez DL, Nugraha $Y$, Carandang J, Pamplona AM, Collard BCY, Ismail AM, Mackill DJ (2015) Accelerating the development of new submergence tolerant rice varieties: the case of CiherangSub1 and PSB Rc18-Sub1. Euphytica. 202:259-268.

Setter TL, Waters I, Wallace I, Bhekasut P, and Greenway H (1989) Submergence of rice I. growth and photosynthetic response to $\mathrm{CO}_{2}$ enrichment of floodwater. Aust J Plant Physiol. 16:251-263.

Sinclair TR, Horie T (1989) Leaf nitrogen, photosynthesis, and crop radiation use efficiency: a review. Crop Sci. 29:90-98.

Sone C, Ito O, Sakagami JI (2012) Characterizing submergence survival strategy in rice via chlorophyll fluorescence. J Agro Crop Sci. 198:152-160.

Tamang BG, Fukao T (2015) Plant adaptation to multiple stresses during submergence and following desubmergence. Int J Mol Sci. 16:30164-30180.

Van Kooten O, Snel JFH (1990) The use of chlorophyll fluorescence nomenclature in plant stress physiology. Photosynth Res. 25:147-150.

Xu K, Mackill DJ (1996) A major locus for submergence tolerance mapped on rice chromosome 9. Mol Breeding. 2:219-224

Xu K, Xu X, Fukao T, Canalas P, Maghirang-Rodriguez R, Heuer S, Ismail AM, Bailey-Serres K, Ronald PC, Mackill DJ (2006) Sub1A is an ethylene responsive-factor-like gene that confers submergence tolerant to rice. Nature. 442:705-708.

Zhu XG, Govindjee, Baker NR, deSturler E, Ort DR, Long SP (2005) Chlorophyll a fluorescence induction kinetics in leaves predicted from a model describing each discrete step of excitation energy and electron transfer associated with Photosystem II. Planta. 223: 114-133. 